\title{
ERECTILE DYSFUNCTION ETIOLOGY AND HORMONAL CHANGES
}

\section{Minireview}

\author{
HeLEN ORRO, KeRSTI KOKK
}

Institute of Anatomy, University of Tartu, Estonia

\section{INTRODUCTION}

Erectile disorder is an inconvenient condition that affects many men and reduces their life quality. It causes problems in private life and may finally lead the patient to deep depression. Hormonal, local biochemical and structural factors of the penis modulate the erectile dysfunction as a neurovascular phenomen. [32]

It is one of the most common forms of male sexual dysfunctions. Approximately $40 \%$ of men over 40 years of age and 1 in 3 men over 70 years of age are suffering from the erectile dysfunction. [9] There are many etiologigal factors that play a role in the etiopathogenesis of the erectile dysfunction. The risk factors which may affect erectile mechanisms are age, vascular factors, metabolic diseases, neurologic diseases, HIV/AIDS and some drugs. Such drugs, for example, are: antiandrogenic, anticholinergic, antidepressants, antihypertensive, major tranquilizers, anxiolytics, and certain medicines/metabolites. [6]

Sexual dysfunction is associated with depression and antidepressant therapy. [12] Roughly $70 \%$ of patients with depressive disorders (23-50\% of men with depression and 33-90\% of women) are having problems with sexual function: a decline in libido, the erectile dysfunction, ejaculation disorders in men and orgasm and menstruation in women. [4] Most antidepressants may cause sexual dysfunction as an adverse effect of treatment. [11]

Psychological and hormonal factors are also important as they participate in the erectile function. [2] According to literature sexual dysfunction is a fre- 
quent problem in hypertensive patients $[18,21,23,5]$ and also common in the patients with chronic kidney disease. [30] 30\% of hypertensive patients have problems with erection. Hypertension and the erectile dysfunction are related diseases the common base of which an endothelial dysfunction. The disorder of endothelium - derived factors may lead to an increase in the vascular smooth muscle contraction. Due to high blood pressure or antihypertensive treatment, hypertension can cause the erectile dysfunction. [21] Vasodilation in response to endothelium - dependent stimuli is inadequate both in the systemic vasculature and the penile arteries. Many antihypertensive drugs may have a drug specific side - effect, which worsens sexual function. [23] Older antihypertensive drugs (diuretics, beta blockers) have harmful effects on the erectile function, but newer drugs (nebivolol, angiotensin receptor blockers) have neutral or even beneficial effects. Phosphodiesterase (PDE) - 5 inhibitors are effective in hypertensive patients and can be safely administered. On has to be careful has to be with alpha blockers and coadministration with nitrates is also contraindicated. [18]

As the erectile dysfunction is mainly a vascular condition, it usually comes before the cardiovascular event by 3-5 years. Due to association with acute coronary syndromes, its early diagnosing gives an opportunity for cardiovascular risk reduction. [9] High LDL, smoking, hypertension and diabetes are risk factors for the coronary heart disease and also for the erectile dysfunction. The erectile dysfunction is a usual problem after the coronary artery disease or myocardial infarction. [5] Obese patients with dyslipidemia, type 2 diabetes mellitus, and/or depression, should be screened for the erectile dysfunction, because of associations between the heart disease, the metabolic disease and the sexual dysfunction. [24] Obesity is confessedly a significant risk factor for the cardiovascular disease, type 2 diabetes, cancer and the erectile dysfunction and low serum sex hormone - binding globulin levels in obesity are associated with the low serum total testosterone. The body mass index and serum total testosterone concentrations are inversely proportional [3] Visceral obesity associates with increased inflammatory responses and thereof predisposes the endothelial dysfunction which together with androgen deficiency are related to the patophysiological mechanisms of the erectile dysfunction. [29]

The increased arterial inflow and the restricted venous outflow, coordinated with corpus cavernosum and penile arterial smooth muscle relaxation, are the hemodynamic processes which are related to the penile erection. [16] The balance of vascular relaxants and constrictors determines the tone of cavernosal smooth muscle cells, which governs the erectile status of the penile tissue. 
Vascular relaxants are important in regulating the tone of the cavernosal smooth muscle. Adenosine is a short - lived vasorelaxant, which relaxes the corpus cavernosum and promotes the penile erection. It works via the cyclic nucleotide second messenger signaling to promote smooth muscle relaxation. Impaired adenosine signaling through $\mathrm{A}(2 \mathrm{~B})$ receptor [22] is associated with the erectile dysfunction. [31]

\section{HORMONAL CAUSES OF ERECTILE DYSFUNCTION}

When men are ageing a progressive and small decline in several sex hormones takes place. It includes testosterone and dehydroepiandrosterone, and the related increases in the luteinizing hormone, the follicle - stimulating hormone, and the sex hormone - binding globulin. [1]

Changes in the body mass index, osteoporosis, sleep and mood disorders are correlated with hormonal changes in the ageing male. [26]

Testosterone, which is the major circulating androgen in male, shows an age - related decline in the ageing male. [7] The age - related changes in reproductive hormones in men are not precipitous as in women. Such gradual changes appear throughout many years. The decline in the serum testosterone level causes many symptoms of hypogonadism, which include: the loss of energy, the decreased libido, the depressed mood, the erectile dysfunction, the decreased muscle mass and strength, the increased fat mass, frailty, osteopenia, and osteoporosis. This condition is also known as an andropause and diagnosed by clinical symptoms and the laboratory-measured serum testosterone levels. [15 ] Disorders at the hypothalamic or pituitary level (hypogonadotropic forms) or the testicular dysfunction (hypergonadotropic forms) can cause hypogonadism. [28]

A remarkable percentage of men over 60 years of age are having serum testosterone levels below the lower limits of young male adults. [27]

The classification of hypogonadism includes primary, secondary, and mixed hypogonadism. The disorders of the testes and therefore low testosterone production and impaired fertility cause primary hypogonadism, whereas disorders of the hypothalamus and the pituitary cause secondary hypogonadism which shows low testosterone and low or inappropriately normal LH and FSH levels. Both defects can cause mixed hypogonadism. Older men usually have secondary or mixed hypogonadism. [27]

Hypogonadism is a condition which may be congenital or acquired. Acquired hypogonadotropic hypogonadism includes the postnatal disorders that 
change or impair the function of gonadotropin - releasing hormone (GnRH) neurons and/or pituitary gonadotroph cells. The most usual causes of acquired hypogonadotropic hypogonadism are pituitary tumors, particularly prolactinoma, pituitary surgery and head trauma, cranial/pituitary radiation therapy and also sellar tumors or the cyst of the hypothalamus or infundibulum, infiltrative, vascular, the iron overload and other disorders. [25]

The luteinizing hormone receptor and the follicle stimulating hormone receptor are important factors in female and male reproduction. [19] Luteinizing hormone (LH), as follicle - stimulating hormone (FSH) and thyroid stimulating hormone (TSH), is the member of the pituitary glycoprotein hormone family and stimulated by gonadotrophin - releasing hormone $(\mathrm{GnRH})$. Our study group investigated the LH receptor expression in the mouse penis, to see if its effects are possible in the penis. We used immunocytochemistry, western blotting and quantitative reverse transcriptase polymerase chain ( $\mathrm{qRT}-\mathrm{PCR}$ ) reaction to detect $\mathrm{LH}$ receptor in the Balb/c mice penis. Positive immunoreaction to $\mathrm{LH}$ was found in the mouse penis urethral epithelium, in the endothelial cells of the cavernous spaces both in corpus spongiosum and corpus cavernosum and also in the testis tissue, which were used as positive control and where positive immunoreaction to the LH receptor was detected in the Leydig cells and in the central part of the seminiferous tubules next to the lumen. The $\mathrm{LH}$ receptor antigen was also present by using Western blotting and quantitative RT-PCR. As we managed to show, using three methods, that the $\mathrm{LH}$ receptor is expressed in the penile tissue of male mice, this finding may suggest, that LH can affect the corpus spongiosum and corpora cavernosa in mice. [13]

Hypogonadism is not the only condition that is connected with the male sexual dysfunction. Other endocrine disorders also associate with it. Severe hyperprolactinemia ( $>35 \mathrm{ng} / \mathrm{mL}$ or $735 \mathrm{mU} / \mathrm{L}$ ), often related to a pituitary tumor, influences the sexual function negatively and impairs sexual desire, testosterone production and through it the erectile function. [17] Hyper- and hypothyroidism may also influence the male sexual health. Premature ejaculation and maybe also the erectile dysfunction are connected with hyperthyroidism. Sexual desire and the impaired ejaculatory reflex are associated with hypothyroidism. $[17,14,8]$ The erectile function and sperm parameters are disadvantageously affected by hypothyroidism, including the sperm count, morphology and motility. Its is recommended to measure thyroid hormones in the patients with the erectile dysfunction and sperm abnormalities. [20] 


\section{SUMMARY}

The erectile dysfunction is a common disorder around the world and it largely influences largely the quality of life.

The individual general health status, the cardiovascular disease, diabetes mellitus, some genitourinary disease, psychiatric or psychological disorders and overall life conditions are risk factors linked with the sexual dysfunction.

As mentioned above, the hormonal changes which take place in time and some drugs are also associated with erectile disorders.

While many etiological factors may cause the erectile dysfunction, it is important to avoid their development and/or reduce their influence to the minimum. It includes preventing atherosclerosis and avoiding diabetes, neurogenic disorders or mental distress. The healthy lifestyle which contains physical activity together with balanced nutrition, nonsmoking and appropriate alcohol consumption is recommendable. [10]

\section{REFERENCES}

1. Araujo A. B., Wittert G. A. (2011). Endocrinology of the aging male. Best Pract Res Clin Endocrinol Metab, Apr; 25(2), 303-19.

2. Breza J. (1995). Diagnosis and treatment of erectile dysfunctions. Bratisl Lek Listy, Dec; 96(12), 642-50.

3. Diaz-Arjonilla M., Schwarcz M., Swerdloff R. S., Wang C. (2008). Obesity, low testosterone levels and erectile dysfunction. Int J Impot Res. 2009, 21(2), 89-98.

4. Gałecki P., Florkowski A., Depko A., Woźniak A., Talarowska M. (2011). Characteristic and treatment of sexual dysfunctions in depression (part I). Pol Merkur Lekarski, 31(183), 193-6.

5. Görge G., Flüchter S., Kirstein M., Kunz T. (2003). Sex, erectile dysfunction, and the heart: a growing problem. Herz. Jun, 28(4), 284-90.

6. Hafez E. S., Hafez S. D. (2005). Erectile dysfunction: anatomical parameters, etiology, diagnosis, and therapy. Arch Androl, 51(1), 15-31.

7. Haring R. (2012). Perspectives for metabolomics in testosterone replacement therapy. J Endocrinol. May 3.

8. Jabaloyas J. M. (2010). Hormonal etiology in erectile dysfunction. Arch Esp Urol, 63(8), 621-7.

9. Jackson G. (2012). Erectile dysfunction and coronary disease: Evaluating the link. Maturitas, 71(1), 20-7.

10. Kaminsky A., Sperling H., Popken G. (2011). Primary and secondary prevention of erectile dysfunction. Urologe A.50(10), 1265-8, 1270.

11. Kennedy S. H., Rizvi S. (2012). Sexual dysfunction, depression, and the impact of antidepressants. J Clin Psychopharmacol, 29(2), 157-64. 
12. Kinzl J. F. (2009). Major depressive disorder, antidepressants and sexual dysfunction. Neuropsychiatr, 23(2), 134-8.

13. Kokk K., Kuuslahti M., Keisala T., Purmonen S., Kaipia A., Tammela T., Orro H., Simovart H. E., Pöllänen P. (2011). Expression of luteinizing hormone receptors in the mouse penis. J Androl, 32(1), 49-54.

14. Krassas G. E., Tziomalos K., Papadopoulou F., Pontikides N., Perros P. (2008). Erectile dysfunction in patients with hyper- and hypothyroidism: how common and should we treat? J Clin Endocrinol Metab, 93(5), 1815-9.

15. Krysiak R., Okopień B. (2012). Pathogenesis and clinical presentation of andropause. Pol Merkur Lekarski, 32(187), 70-3.

16. Lamina S., Agbanusi E., Nwacha R. C. (2011). Effects of aerobic exercise in the management of erectile dysfunction: a meta analysis study on randomized controlled trials. Ethiop J Health Sci. 21(3), 195-201.

17. Maggi M., Buvat J., Corona G., Guay A., Torres L. O. (2012). Hormonal Causes of Male Sexual Dysfunctions and Their Management (Hyperprolactinemia, Thyroid Disorders, GH Disorders, and DHEA). J Sex Med Apr 23.

18. Manolis A., Doumas M. (2012). Antihypertensive Treatment and Sexual Dysfunction. Curr Hypertens Rep. May 12.

19. Menon K. M., Menon B. (2012). Structure, function and regulation of gonadotropin receptors - a perspective. Mol Cell Endocrinol. 356(1-2), 88-97.

20. Nikoobakht M. R., Aloosh M., Nikoobakht N., Mehrsay A. R., Biniaz F., Karjalian M. A. (2012). The role of hypothyroidism in male infertility and erectile dysfunction. Urol J. 9(1), 405-9.

21. Nunes K.P., Labazi H., Webb R. C. (2012). New insights into hypertensionassociated erectile dysfunction. Curr Opin Nephrol Hypertens, 21(2), 163-70.

22. Phatarpekar P. V., Wen J., Xia Y. (2010). Role of adenosine signaling in penile erection and erectile disorders. J Sex Med. 7(11), 3553-64.

23. Reffelmann T., Kloner R.A. (2006). Sexual function in hypertensive patients receiving treatment. Vasc Health Risk Manag. 2(4):447-55.

24. Ryan J. G., Gajraj J. (2012). Erectile dysfunction and its association with metabolic syndrome and endothelial function among patients with type 2 diabetes mellitus. J Diabetes Complications, 26(2), 141-7.

25. Salenave S., Trabado S., Maione L., Brailly-Tabard S., Young J. (2012). Male acquired hypogonadotropic hypogonadism: Diagnosis and treatment. Ann Endocrinol (Paris), 73(2), 141-6.

26. Schulman C., Lunenfeld B. (2002). The ageing male. World J Urol, 20(1), 4-10.

27. Surampudi P. N., Wang C., Swerdloff R. (2012). Hypogonadism in the aging male diagnosis, potential benefits, and risks of testosterone replacement therapy. Int J Endocrinol. 625434.

28. Zitzmann M., Nieschlag E. (2000). Hormone substitution in male hypogonadism. Mol Cell Endocrinol, 161(1-2), 73-88. 
29. Traish A. M., Feeley R. J., Guay A. (2009). Mechanisms of obesity and related pathologies: androgen deficiency and endothelial dysfunction may be the link between obesity and erectile dysfunction. FEBS J., 276(20), 5755-67.

30. Vecchio M., Navaneethan S. D., Johnson D. W., Lucisano G., Graziano G., Saglimbene V., Ruospo M., Querques M., Jannini E. A., Strippoli G. F. (2010). Interventions for treating sexual dysfunction in patients with chronic kidney disease. Cochrane Database Syst Rev.(12), CD007747.

31. Wen J., Xia Y. (2012). Adenosine signaling: good or bad in erectile function? Arterioscler Thromb Vasc Biol, 32(4), 845-50.

32. Williams S. K., Melman A. (2012). Novel therapeutic targets for erectile dysfunction. Maturitas, 71(1), 20-7.

\section{Aadress for correspondence:}

Helen Orro

Institute of Anatomy

University of Tartu

Ravila 19, 50411 Tartu

E-mail: helen.orro@ut.ee 